\title{
Vitamin D Status Relative to Diet, Lifestyle, Injury, and Illness in College Athletes
}

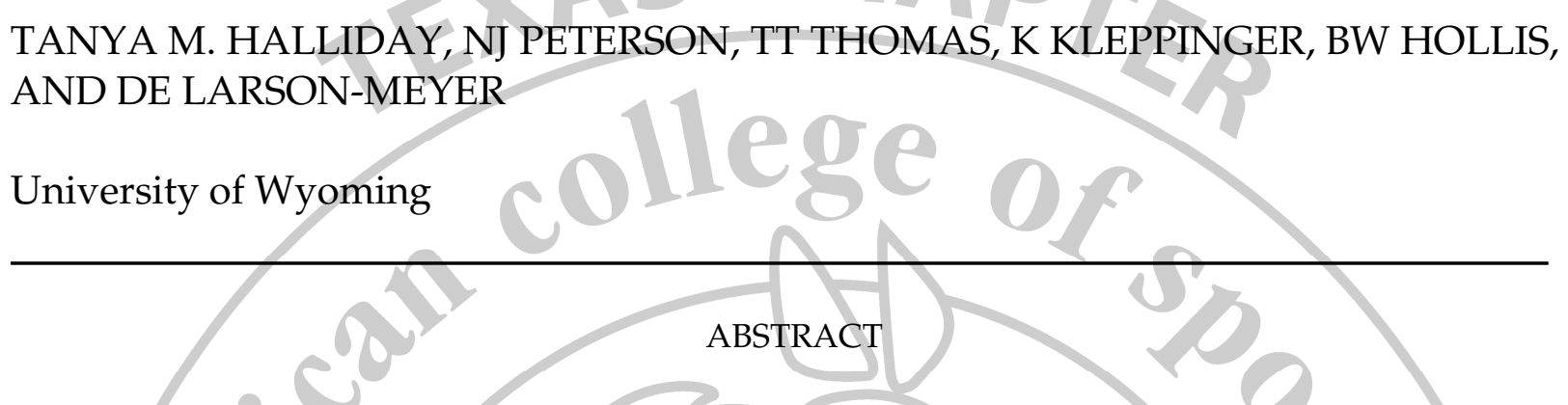

Vitamin D deficiency is endemic in the general population; however, there is much to be learned about the vitamin D status of athletes. The purposes of this study were to assess the prevalence of vitamin D insufficiency in collegiate athletes and to determine whether $25(\mathrm{OH}) \mathrm{D}$ concentrations are related to vitamin D intake, sun exposure, body composition, and risk for illness or athletic injury. $25(\mathrm{OH})$ vitamin $\mathrm{D}$ concentrations were measured in 41 athletes (18 men/23 women, 12 indoor/29 outdoor athletes) throughout the academic year. Dietary intake and lifestyle habits were assessed via questionnaire, bone density was measured by dual energy $\mathrm{x}$-ray absorptiometry, and injury and illness were documented as part of routine care. The $25(\mathrm{OH}) \mathrm{D}$ concentrations changed across time $(\mathrm{P}=0.001)$ and averaged $49.0 \pm$ $16.6,30.5 \pm 9.4$, and $41.9 \pm 14.6 \mathrm{ng} / \mathrm{mL}$ (mean $\pm \mathrm{SD}$ ) in the fall, winter, and spring, respectively, and were higher in outdoor versus indoor athletes in the fall $(\mathrm{P}<0.05)$. Using $40 \mathrm{ngImLj} 1$ as the cutoff for optimal status, $75.6 \%, 15.2 \%$, and $36.0 \%$ of athletes had optimal status in the fall, winter, and spring, respectively. $25(\mathrm{OH}) \mathrm{D}$ concentrations were significantly $(\mathrm{P}<0.05)$ correlated with multivitamin intake in the winter $(\mathrm{r}$ $=0.39)$ and tanning bed use in the spring $(\mathrm{r}=0.48)$; however, status was otherwise not related to intake, lifestyle factors, or body composition. $25(\mathrm{OH}) \mathrm{D}$ concentrations in the spring $(\mathrm{r}=-0.40, \mathrm{P}=0.048)$ was correlated with frequency of illness. Our results suggest that collegiate athletes can maintain sufficient status during the fall and spring but would benefit from supplementation during the winter to prevent seasonal decreases in $25(\mathrm{OH}) \mathrm{D}$ concentrations. Results further suggest that insufficient vitamin D status may increase risk for frequent illness. Future research is needed to identify whether vitamin D status influences injury risk during athletic training or competition.

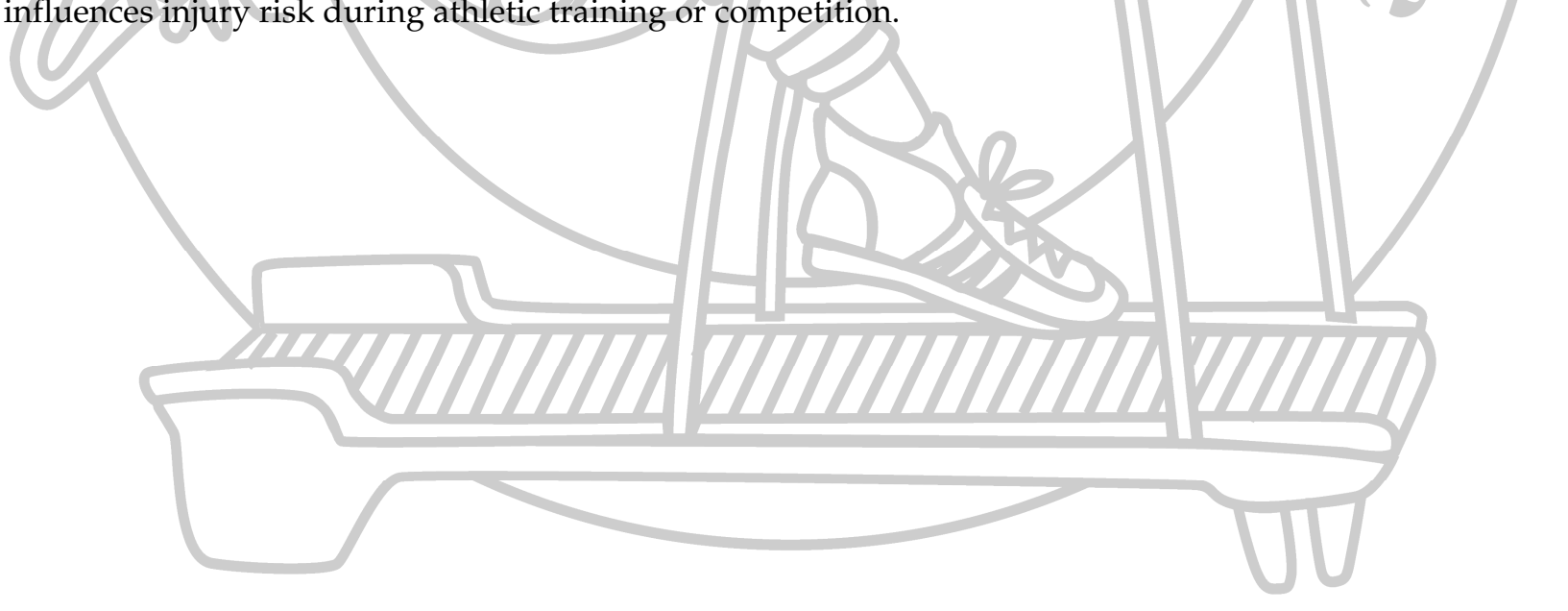

